\title{
OFICINAS DE ESTAMPARIA
}

\author{
Reinilda de Fátima Berguenmayer Minuzzi \\ Universidade Federal de Santa Maria \\ reibmin@yahoo.com.br \\ Cíntia Medianeira Bitencourt de Lima \\ Universidade Federal de Santa Maria \\ cmbdelima@yahoo.com.br \\ Ceila Teresinha Bitencourt de Bittencourt \\ Universidade Federal de Santa Maria \\ ceilabbittencourt@gmail.com
}

\begin{abstract}
Resumo: $O$ presente artigo se propõe a trazer um relato sobre a experiência discente no âmbito do projeto de extensão Oficinas Comunitárias de Estamparia, que teve foco na produção plástica em estamparia e na reflexão diante desta por parte de seus atores. No âmbito geral, o projeto prevê a realização de uma série de oficinas de estamparia em escolas, centros comunitários e no próprio espaço institucional (laboratórios) no sentido de proporcionar o aprendizado de processos e técnicas pelos participantes, capacitando-os a desenvolver autonomamente produções e aplicações práticas na área do design de superfície e estamparia, inclusive como possibilidade de geração de renda, constituindo um retorno à comunidade relativamente à produção da cultura material, a partir do conhecimento sobre a mesma. A metodologia do projeto tem abordagem qualitativa e a exposição da proposta, neste caso, aplicada no ensino fundamental, ocorreu através de exemplificação por meio de projetos e peças realizados na área, seguida da prática específica por parte dos estudantes. Finalizou-se com a exposição de trabalhos e manifestação dos participantes em relação à experiência vivenciada, avaliando conjuntamente a experiência.
\end{abstract}

Palavras-chave: Design de Superfície, Estamparia, Oficinas Comunitárias.

Abstract: This article aims to bring a report on the student experience
within the project extension Stamping Community Workshops, which had
focused on plastic production stamping and reflection on this by its actors.
In the general framework, the project provides for a series of workshops
crack in schools, community centers and institutional space itself
(laboratories) to provide learning processes and techniques by the 
participants, enabling them to autonomously develop production and practical applications in surface design and printing area, including a possibility of generating income, making a return to the community in relation to the production of material culture, from the knowledge of the same. The project methodology is qualitative approach and exposure of the proposal, in this case, applied in elementary education occurred through exemplification through projects and pieces made in the area, then the specific practice by student. This was completed with the exhibition of works and expressions of participants in relation to lived experience, jointly assessing the experience.

Key-words: Surface Design, Stamping, Community Workshops

\section{INTRODUÇÃO}

Considerando a trajetória de graduação com foco em Design de Superfície e Estamparia na Universidade Federal de Santa Maria/UFSM, RS e o histórico de pósgraduação na mesma área, ambas iniciada já nos anos 90 , a proposta desta ação centra-se na possibilidade de construir conhecimento aplicado nesta área específica junto à comunidade, pela realização de uma série de oficinas de estamparia em escolas, centros comunitários e no próprio espaço institucional da UFSM. Nesse contexto, propõe estender para outros níveis de ensino (formal e não formal) a criação de competências na área específica, escopo do projeto, constituindo uma relação consistente com a pesquisa e extensão a partir da formação universitária.

No caso da UFSM, o fato de essa ser uma área bastante específica em que poucas instituições no país se ocupam, remete à importância de divulgar resultados e produções, ao longo de sua história. Portanto, a realização de oficinas e cursos de extensão possibilita a aproximação da comunidade a este campo. A ação tem base no projeto de extensão "Oficinas Comunitárias de Estamparia", iniciado em 2010, a partir de atividades realizadas pelo Laboratório de Pesquisa Arte e Design/LAD-UFSM, em parceria com o Laboratório de Iniciação e Criatividade em Artes/LICA-UFSM. Como meta, buscou-se a integração de outros setores da comunidade, normalmente com pouco acesso a atividades culturais e artísticas, como exemplo, o público adolescente e infantil vinculado a escolas públicas.

A oficina apresenta-se, portanto, como uma possibilidade a explorar, no âmbito do design de superfície, com inserção em práticas educativas e culturais, podendo ser um elemento motivador para propostas diferenciadas em encontros/atividades de ensino formal e não formal no atual contexto sociocultural da cidade e região.

\section{BASES DA ESTAMPARIA E DESIGN DE SUPERFÍCIE}

Segundo Rubim (2004), tanto o design têxtil, o projeto para papelaria, o design cerâmico ou de suportes materiais como plásticos e emborrachados, assim como aqueles que incluem desenhos e cores sobre utilitários (ex. as louças) são áreas abrangidas pelo design de superfície que também podem participar como complemento do design gráfico. Este último pode envolver o design de superfície quando trabalhar uma ilustração, no fundo de peças gráficas ou ainda em web design.

Vale lembrar que a estamparia permanece como um recurso diferenciador, fazendo-se presente nos mais diversos produtos ou objetos, desde sapatos, 
revestimentos cerâmicos, bolsas, peças de vestuário, utilitários em geral, entre outros. Com o impulso de setores como a moda e das últimas tendências e desenvolvimentos tecnológicos na área têxtil, por exemplo, o campo ganha espaço de pesquisa também no resgate de procedimentos e métodos de artesãos e artistas em sua prática.

Fazem parte dos primórdios da atividade os métodos artesanais de uso de blocos de madeira, já no final do século XVII, seguido pela técnica do estêncil, um tipo de máscara vazada que deixa em aberto áreas onde se deseja estampar. Após, surgiram os rolos de cobre gravados em um processo que permitia uma maior escala de produção. Hoje, com o desenvolvimento tecnológico de processos industriais, aliados à informatização, as possibilidades se alargam, eliminando muitas restrições em termos de execução de desenhos de estamparia, sobretudo com a introdução da impressão digital em diferentes suportes (tecido, vidro, laminados vinílicos, madeira, cerâmica, metal, entre outros). Contudo, o resgate e o exercício dos procedimentos manuais e artísticos tem sido uma busca das empresas para gerar inovação e diferenciação no produto (MINUZZI, 2003; RÜTHSCHILLING, 2008; EDWARDS, 2012).

Abordando os aspectos de desenvolvimento e criação na área, Rüthschilling (2008) apresenta o conceito de módulo como a menor área que envolve todos os elementos que formam o desenho, sendo que a composição visual depende da disposição dos elementos dentro do módulo (motivos) e da articulação entre os módulos, criando o padrão, conforme a estrutura já estabelecida de repetição. Também Lupton (2008) coloca como base da padronagem a repetição do mesmo elemento. Nesse contexto, Rubim (2004) menciona que, em se tratando de formas simples, não é preciso nenhum conhecimento específico para identificar a imagem em repetição, ou seja, o módulo; já o rapport pode ser bastante elaborado aparecendo frequentemente em tecidos estampados de alto valor associado.

A habilidade de se alcançar bons resultados com a repetição se adquire com a experiência do indivíduo neste tipo de projeto. Ao exercitar-se tal processo, é facilitada a compreensão intelectual do funcionamento visual de uma imagem que se repete horizontal e verticalmente. Há técnicas simples que facilitam esse entendimento e possibilitam posteriormente estabelecer relações com técnicas avançadas para construção do rapport.

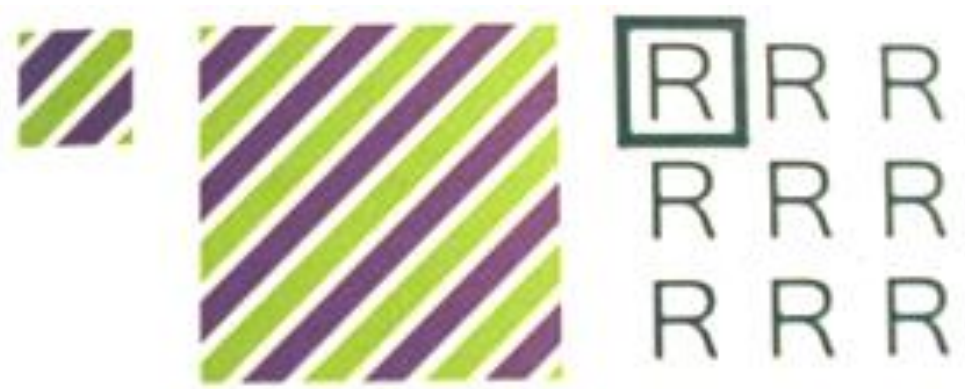

Figura 1: Módulo e repetição para determinação do rapport. Fonte: RÜTHSCHILLING, 2008. 


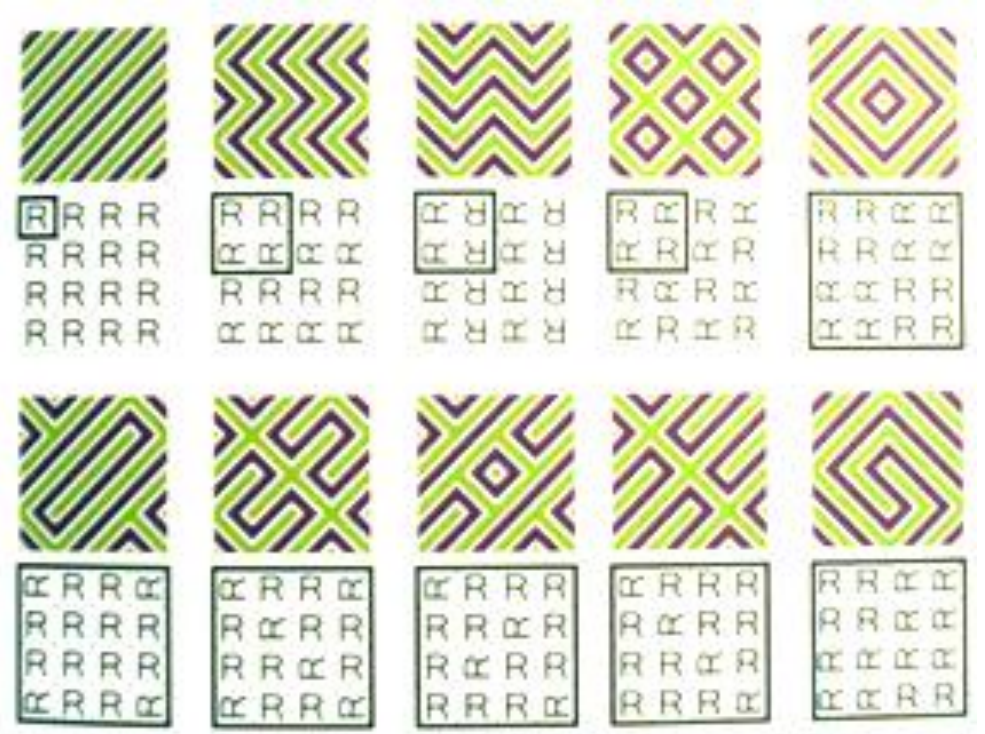

Figura 2: Variações dos sistemas de repetição modular.

Fonte: RÜTHSCHILLING, 2008.

A cor, igualmente, é considerada como um dos principais elementos responsáveis pelo resultado de um projeto em design de superfície, segundo Rubim (2004), sendo, para a autora, um elemento determinante da atração ou não do usuário pelo objeto ou peça. Da mesma forma, reforça a importância do referencial visual distinguindo de referências conceituais. O que deve ser levado em consideração no desenvolvimento do processo não são ideias, conceitos ou livres associações, e sim, os indícios apresentados por essa referência. Muitas vezes, no decorrer do processo, ocorre uma sensação incômoda de se estar produzindo simplesmente uma cópia e que aquele trabalho não vai gerar nada de novo. Porém, com a possibilidade de aprofundar o processo criativo, permite-se o surgimento de novos e surpreendentes resultados.

\section{DESENVOLVIMENTO DA OFICINA}

Considerando os aspectos fundamentais específicos da linguagem, realizou-se uma oficina prática na Escola Municipal Antônio Gonçalves do Amaral, no Bairro Camobi, em Santa Maria, RS. As atividades foram desenvolvidas com alunos do 5음 ano com média de idade entre 10 e 11 anos, levando em consideração a promoção de experiências diversificadas para essa faixa etária nos campos das artes e do design (LUPTON, 2008).

A proposta de trabalho foi pensada para aplicação em papelaria e estampa localizada para camisetas, pela facilidade de apreensão e execução. Para seu desenvolvimento, foram mostrados trabalhos na área como referencial visual para entendimento da proposta, sendo explanadas as diferenças entre a estampa localizada e a estampa corrida (contínua). Os materiais utilizados e distribuídos para cada grupo de alunos foram: tintas guaches nas cores primárias, isopor, tesoura, papel cartão, papel jornal, pincéis, rolinho de espuma e potes com água.

Tratando do processo de geração de alternativas em estamparia, durante a prática realizada na oficina, igualmente foi explanado sobre a criação de formatos e a desconstrução formal para se chegar a outras estruturas e configurações. Assim, para o desenvolvimento em papelaria, partiu-se de formas geométricas conhecidas, que foram reconfiguradas, gerando novos formatos a partir das estruturas iniciais 
(quadrado, retângulo, círculo, triângulo) propostas. Já para aplicação em camisetas, com estampa localizada, e com a possibilidade de interpretação partindo de uma imagem conhecida, artificial ou da natureza, os participantes escolheram o referencial visual "pássaros" para trabalhar os motivos. Neste aspecto foi orientado quanto à análise visual do referencial e sua posterior síntese gráfica como procedimento inicial para elaboração do formato para aplicação em estamparia.

Acerca do assunto, Edwards (2012) comenta que os pássaros são temas bastante escolhidos pelos designers têxteis. $\mathrm{O}$ autor menciona que simbolismos estão associados a determinadas espécies e também às crenças e superstições em diferentes culturas.

Por outro lado, durante o desenvolvimento da atividade prática tratou-se com os alunos participantes acerca da escolha das cores e suas particularidades, abordando sobre cores primárias, cores secundárias, bem como os tipos de texturas, que tipos de materiais podem ser utilizados para confecção de carimbos para obter diferentes texturas. Questionou-se a respeito de exemplos de estampas e texturas encontradas no dia a dia, isto é, onde se percebe a presença destes elementos.

Após a exposição de exemplos práticos realizados em diversas técnicas e procedimentos, a atividade prática foi proposta para ser desenvolvida em grupo, sendo os participantes organizados de acordo com suas afinidades.

\subsection{Aplicação em processos manuais de estamparia}

Uma das propostas desenvolvidas com os estudantes foi a aplicação em papelaria através de produção de formatos geométricos e texturas, através do uso de estêncil e carimbos manuais. Para tal, foram explicados diversos conceitos, tais como: a repetição, a textura, o estudo das formas através da desconstrução formal a partir das formas básicas como o triângulo, o quadrado e o círculo como já mencionado anteriormente. Os carimbos foram construídos com isopor e outros materiais acessíveis, aplicando os estudos de formas realizados; o estêncil com máscaras com papel cartão. Foi também questionado em quais suportes ou superfícies poderia ser empregada a papelaria.

Nesse sentido, Rubim (2004) comenta que qualquer superfície pode se adequar a um projeto, pois o design de superfície pode surgir das mais variadas formas, como em superfícies contínuas (papéis de presente e de parede, tecidos a metro, carpetes, entre outros). Assim, é fundamental conhecer como criar e projetar um desenho, uma vez que uma imagem relativamente simples pode assumir o status de uma composição interessante e agradável, tendo em vista ter sido bem explorada, transformando-se em uma padronagem, cujo desenho básico aparece em repetição e da mesma forma acontece com a cor. Para a autora, a cor tem o poder de transformar um desenho de pouco destaque em um ótimo trabalho, como também pode desvalorizar um trabalho muito bem elaborado.

A reflexão trouxe elementos presentes em Rüthschilling (2008), que lembra que o design de superfície envolve figuras ou motivos, elementos de preenchimento e de ritmo. Os motivos em estamparia são formas não interrompidas que se destacam em primeiro plano possibilitando alternância entre figura e fundo e podem surgir várias vezes na composição em variações de tamanho, posição e pequenas modificações na forma. Eles vêm carregados de mensagens visuais e permitem, ao espectador, livre interpretação. 
Os elementos de preenchimento são texturas, grafismos, entre outros, que correspondem a tratamentos dos fundos isoladamente ou interagindo com motivos distribuídos sobre ele. O ritmo por sua vez, apresenta força visual, alcançada pela configuração, posição, cor, entre outros aspectos referentes aos elementos no espaço. Nesse caso, a repetição constrói a estrutura formal que propaga o tratamento visual que cobre a superfície. Rubim (2004) coloca que um desenho em repetição é utilizado nas indústrias e para se referir a esta forma de representação utiliza-se o termo originariamente francês rapport. Os padrões em rapport podem apresentar diversas formas de apresentação, desde as mais simples até as mais complexas.

$\mathrm{Na}$ proposta para desenvolver estampa localizada na oficina em questão, primeiramente foi explanado sobre a localização do motivo na camiseta. Depois, com base em imagens de revistas, os alunos optaram por trabalhar com figuras de pássaros, que foram interpretados através da técnica de colagem. Após, foram confeccionadas máscaras com papel cartão e carimbos com isopor com a finalidade de executar a estampa para a camiseta.

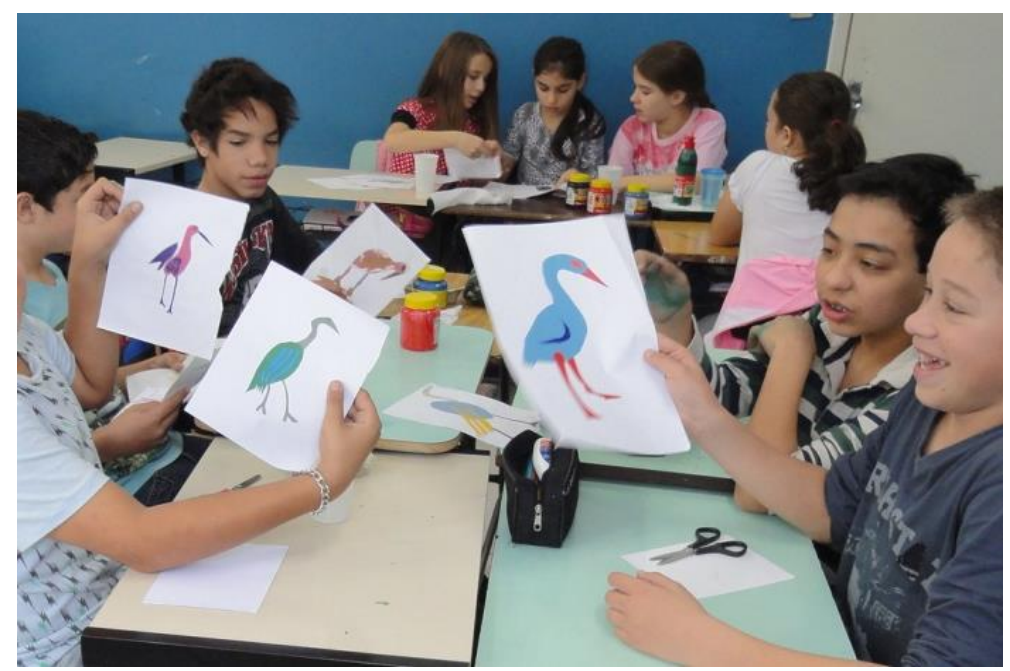

Figura 3: Demonstração da síntese formal, com análise dos elementos visuais.

Fonte: Elaborado pelo autor, com base na pesquisa realizada.

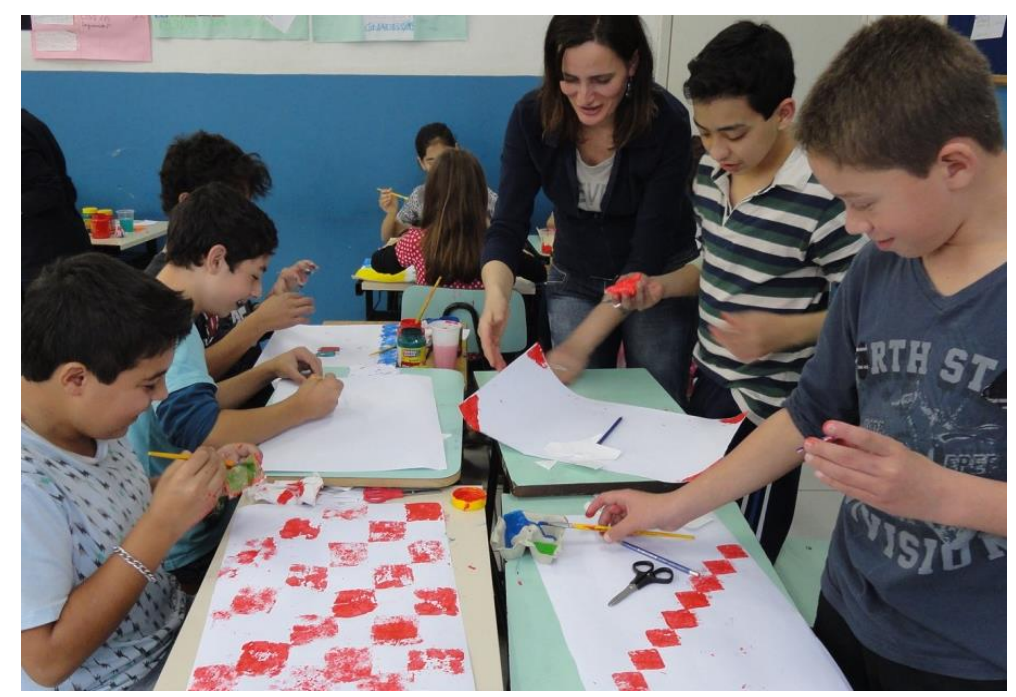

Figura 4: Prática de impressão com carimbos e aplicações em papelaria.

Fonte: Elaborado pelo autor, com base na pesquisa realizada. 


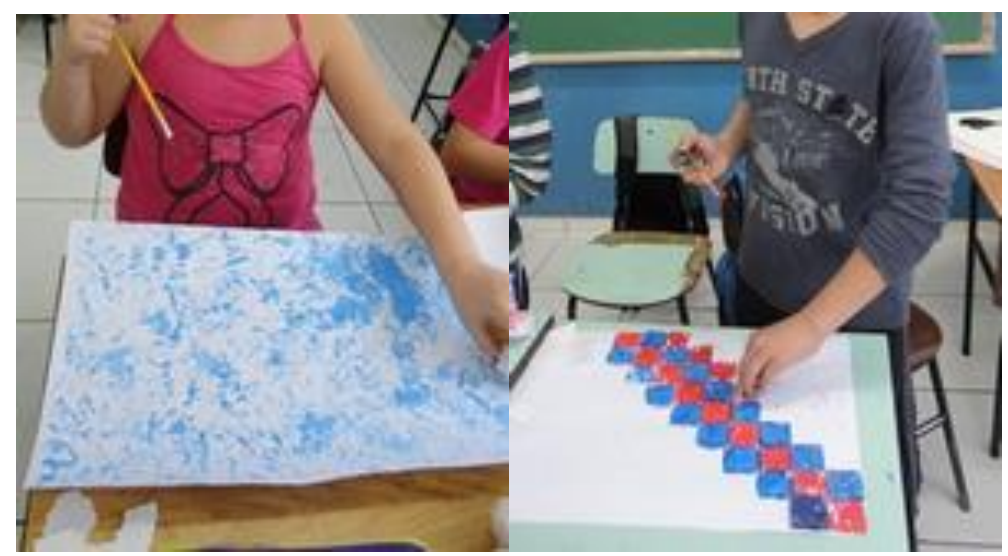

Figura 4: Experimentação de textura e estudo de ritmo e repetição.

Fonte: Elaborado pelo autor, com base na pesquisa realizada.

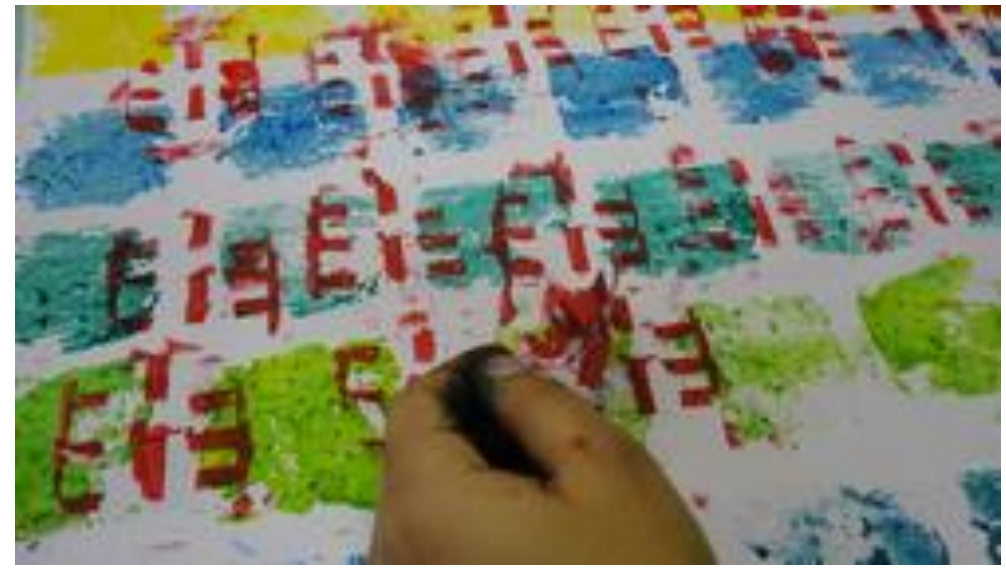

Figura 5: Estamparia experimental com Estêncil.

Fonte: Elaborado pelo autor, com base na pesquisa realizada.

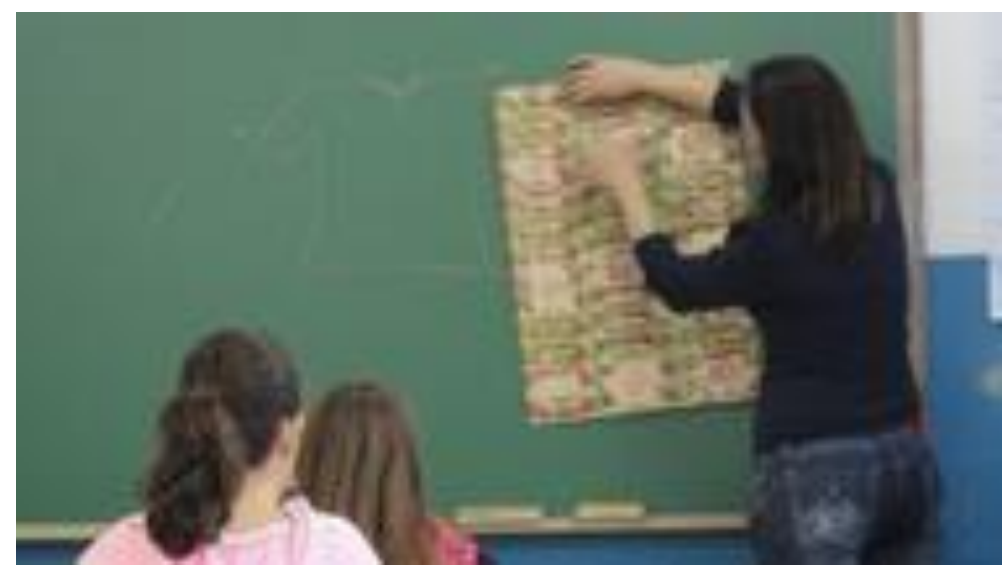

Figura 6: Demonstração e prática da proposta para papelaria.

Fonte: Elaborado pelo autor, com base na pesquisa realizada. 


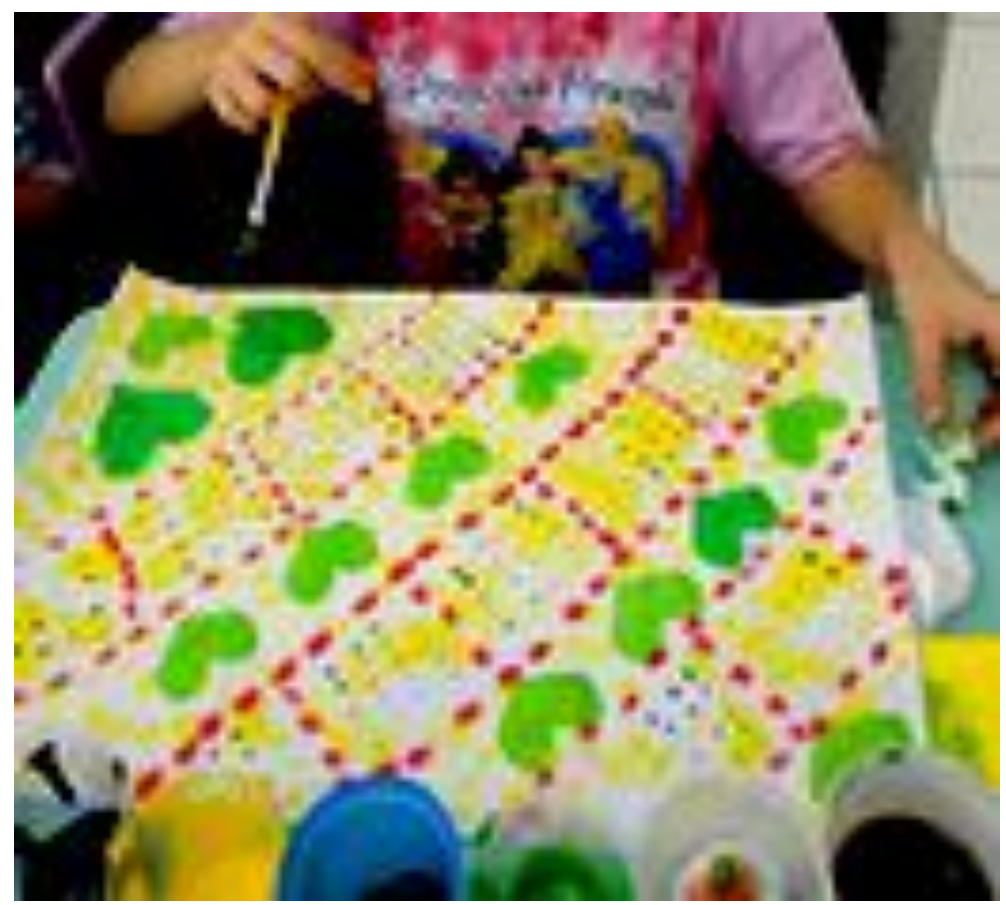

Figura 6: Demonstração e prática da proposta para papelaria.

Fonte: Elaborado pelo autor, com base na pesquisa realizada.

A oficina resultou em produções do grupo participante que foram expostas no local (escola) possibilitando uma reflexão sobre as mesmas. Na oportunidade, enfatizou-se o reconhecimento da área em questão, o design de superfície como campo de formação e atuação profissional e sua presença constante e diversificada no cotidiano de todos, bem como a constatação das distintas formas em que se manifesta neste contexto.

\section{CONCLUSÃO}

A atividade realizada como Oficina de Estamparia teve boa recepção pelos participantes (alunos) e a Escola. Os estudantes não tiveram dificuldade de entendimento da prática, pois a explanação inicial e a diversidade de referenciais visuais facilitaram o processo. Os questionamentos em relação à repetição como responsável pelo ritmo do desenho evidenciaram o envolvimento dos participantes com a proposta. Os trabalhos finais ficaram variados em forma e cor e os alunos demonstraram satisfação com o resultado.

Considera-se que a experiência possibilitou uma maior vivência na área de atuação em design de superfície, proporcionando o contato com outros níveis de ensino e permitindo uma inter-relação entre ensino, pesquisa e extensão. As atividades desenvolvidas estimularam novas experiências aos participantes da oficina de estamparia (alunos do ensino fundamental), possibilitando ampliar sua percepção em relação a outras formas de experimentação no campo do design e da arte.

Os estudantes refletiram sobre a área em questão, reconhecendo sua presença no dia a dia, em diferentes objetos e superfícies. Os exemplos abordados, também presentes no seu cotidiano, como o design aplicado à papelaria e estamparia de camiseta, foram, assim, de fácil assimilação.

Os resultados do projeto foram positivos e pretende-se estabelecer sua continuidade em novas experiências, envolvendo diferentes atores. 


\section{REFERÊNCIAS}

EDWARDS, Cliwe. Como compreender design têxtil: guia para entender estampas e padronagens. São Paulo: SENAC, 2012.

LUPTON, Ellen; LUPTON, Julia. Eu que fiz. São Paulo: Cosac Naify, 2008.

MINUZZI, Reinilda de Fátima Berguenmayer. Estampando diferenciais: pesquisa criativa no design de superfície. Disponível na Internet por http em: $<$ http://diegopiovesan.files.wordpress.com/2010/07/estampando-diferenciais-

pesquisa-criativa-no-design-de-superficie.pdf >. Acesso em 11 fev. 2014.

RUBIM, Renata. Desenhando a superfície (Coleção Textos Design) São Paulo: Rosari, 2004.

RÜTHSCHILLING, Evelise Anicet. Design de Superfície. Porto Alegre: Ed. da UFRGS, 2008. 